\title{
Prejuzgamiento o no en aplicación de medidas cautelares en los procesos por competencia desleal en Colombia
}

\author{
Prejudgment or not in application of precautionary measures in the processes \\ for unfair competition in Colombia
}

LAYS ALEJANDRA MEZA YANCES

Abogada.

Especialista en Derechos Procesal. Universidad de San Buenaventura Seccional Cartagena

Fecha de recepción: marzo de 2019

Fecha de aprobación: julio de 2019

Para citar este artículo / To reference this article Meza, L.A. (2019) Prejuzgamiento o no en aplicación de medidas cautelares en los procesos por competencia desleal en Colombia. Inciso, 21; 19-40.

Resumen

En este artículo se abordará el tema de las medidas cautelares, pasando por sus generalidades, características y aplicación de forma general en el proceso colombiano hasta llegar a su práctica en los procesos por competencia desleal. Este trabajo es una investigación jurídica, con método deductivo, descriptivo y no experimental que busca examinar la forma como son aplicadas las medidas cautelares en los procesos por competencia desleal y de paso despejar el interrogante: ¿las medidas cautelares decretadas en procesos por competencia desleal constituyen prejuzgamiento? Disyuntiva que tiene posiciones a favor y en contra pero que para el caso se desarrollará la segunda, para llegar a la conclusión de que no se considera un atentado a los derechos fundamentales de defensa y contradicción dentro de un proceso de este tipo.

Palabras clave: Administración de justicia, Aplicación de la ley, Competencia económica, Medidas proteccionistas, Sentencia judicial. 


\begin{abstract}
This article will address precautionary measures, going through their generalities, characteristics and application, in a general way, in the Colombian process, until arriving at in its practice to unfair competition processes. This work is a legal investigation, with a deductive, descriptive and non-experimental method that seeks to examine how precautionary measures are applied in processes by unfair competition, and in addition, making clear the question: Do precautionary measures decreed in processes by unfair competition constitute prejudging? A dilemma that has positions for and against, but that here, only the latter will be developed, to reach the conclusion that it is not considered as an attack on the fundamental rights of defense and contradiction within such type of process.
\end{abstract}

Keywords: Administration of justice, Law enforcement, Economic competence, Protectionist measures, Court ruling.

\title{
INTRODUCCIÓN
}

En vista de las demoras de la justicia para resolver los procesos y que en virtud de esa tardanza, se puedan ocasionar perjuicios o amenazas de su consumación, aparecieron las medidas cautelares para tratar de contrarrestar dichos daños que se pueden generar antes o durante la litis.

Para que una medida cautelar sea decretada, se necesita que el juzgador observe que realmente se encuentra en presencia de una vulneración de un derecho por medio de pruebas, esto a su vez genera inquietudes a los actores del proceso, sobre todo quien soporta la medida, ya que se preguntan si una providencia anticipada que determina posibles daños y su inmediata protección puede constituir o no un veredicto definitivo sobre el curso de la litis y su posterior sentencia, lo que de alguna manera, podría darles cierta incertidumbre jurídica.

Los procesos por competencia desleal por ser procesos declarativos no están exentos de ese interrogante frente al decreto de medidas cautelares, de lo cual no existe evidencia de que esta creencia sea verás, pues los pronunciamientos de las autoridades jurisdiccionales encargadas de dirimir estos asuntos han reiterado que el prejuzgamiento no es una característica de las medidas cautelares, lo cual no define ningún proceso judicial.

\section{Definición, Características y aplicación de las medidas cautelares en el Proceso colombiano}

Antes de adentrarnos en la aplicación de las medidas cautelares en los procesos por competencia desleal en Colombia, se hace necesario establecer en primer término, un concepto general sobre los mismos. La doctrina se ha pronunciado frente a esta figura destacándose entre ellos los siguientes: 
Piero Calamandrei (1984) determinó que las medidas cautelares surgen“(...) de la existencia de un peligro de daño, derivado del retardo de una providencia jurisdiccional definitiva (peliculum in mora)" (p.40)

Para el doctor Jairo Parra Quijano (2013), las medidas cautelares es el punto medio entre dos problemas que aquejan a la justicia y lo desarrolla así:

Las providencias cautelares representan una conciliación entre las dos exigencias, frecuentemente opuestas de la justicia: la de la celeridad y la de la ponderación; entre hacer las cosas pronto pero mal, y hacerlas bien pero tarde, las providencias cautelares tienden, ante todo, a hacerlas pronto dejando el problema de bien y mal, esto es, la justicia intrínseca de la providencia, se resuelva más tarde con la necesaria ponderación, en las reposadas formas del proceso ordinario. (p.301)

Desde el punto de vista constitucional tenemos que "desde esta perspectiva, las medidas cautelares se ofrecen como una valiosa herramienta para garantizar la materialización de los derechos, cualquiera que sea su linaje: fundamentales, reales, patrimoniales, etc., diseñadas a la medida de una Constitución que va más allá de su mero reconocimiento, para comprometerse con su realización." (Álvarez, 2014, p.15)

De lo citado se puede deducir que, las medidas cautelares son todas aquellas actuaciones tendientes bien sea para proteger los derechos que se encuentren presuntamente vulnerados o mitigar los daños ya causados por determinados actos. Su ejercicio depende de la orden de una autoridad competente en el proceso en curso o inclusive extraprocesalmente.

Pero las medidas cautelares no emanan exclusivamente de la voluntad del juzgador, como un capricho o un antojo procesal, su decisión obedece a un análisis fundamentado que hace éste teniendo en cuenta la apariencia de buen derecho o "fumus bonis iuris" dependiendo del caso particular, siendo ese el principio por excelencia de las medidas cautelares.

La llamada apariencia de buen derecho ha sido aproximada en su definición por Álvarez (2014) así:"Si el derecho cuya protección o satisfacción se reclama luce factible o probable; si el juez encuentra que el soporte probatorio da pie para considerar -prima facie- que la pretensión eventualmente podría ser concedida (...)" (p.20)

Por lo expuesto, no se puede dejar de lado que la base para que el juez decrete o no una medida cautelar son las pruebas con que el solicitante sustente la pretensión de la medida. En la construcción del concepto Álvarez (2014) manifestó que "esa apariencia, como se anticipó, usualmente emerge de las pruebas aportadas por el interesado en la medida." (p.20) 
De manera que, la imposición de medidas cautelares es una garantía contemplada en la Constitución y la Ley para salvaguardar los derechos que por unas u otras circunstancias se hallen trasgredidos o en peligro de estarlo, por lo que el juzgador en su sabiduría logra identificar componentes que permiten vislumbrar esas falencias y decreta la medida que considere pueda contrarrestar el daño aparente.

Ahora bien, estas medidas cautelares poseen características que las definen y las hace una figura procesal distinta de las demás de acuerdo a su función, como lo son la provisionalidad, la accesoriedad, la instrumentalidad y el carácter preventivo, de los cuales pasaremos a examinar.

La primera se relaciona con la temporalidad de la medida, por lo que hay que dejar en claro que su imposición no se perpetúa en el tiempo; sus funciones ya sean extraprocesales o procesales, finalizan una vez se obtenga una sentencia definitiva en la Litis o una vez se cumpla el objetivo para lo cual fue decretada. Dicho en palabras de Álvarez (2014) "Son provisionales por cuanto se adoptan mientras se profiere la decisión que resuelva definitivamente el conflicto o se satisfaga cabalmente el derecho sustancial." (p.26)

Otra de las cualidades es la provisionalidad que permite que la medida cautelar a imponer es modificable de acuerdo a la forma de su imposición en el proceso específicamente, que perjudica ostensiblemente a quien la soporta. Un ejemplo de ello lo encontramos en el artículo 600 de nuestro Código General del Proceso que contempla la reducción de los embargos y secuestros.

Por otro lado, la accesoriedad, otra de las características de las medidas cautelares, quiere significar la dependencia de estas de un proceso para que puedan hacerse efectivas o dicho de otro modo "en nuestro derecho positivo y por regla general, las medidas cautelares son accesorias de un proceso principal, en donde el juez ni juzga ni prejuzga dado su carácter subsidiario." (Uribe, 2014, p.45). Aunque existen medidas cautelares autónomas, es decir, que anteceden al proceso, de igual forma sus efectos y consecuencias se contemplarán estando en curso una actuación posterior dentro de un proceso judicial.

Ahora, la instrumentalidad de una medida depende del proceso "porque están en función de la pretensión, la cual, por consiguiente, determina la clase de medida cautelar." (Álvarez, 2014, p.30). Lo anterior, en razón de que cada medida cautelar busca proteger un derecho específico y su efectividad va a depender del proceso de donde se ordene, para que realmente cumpla su finalidad.

Y por último, el carácter preventivo es una de las características de las medidas por cuanto es la causa principal de la creación de esta figura, anticipación, estar preparado antes de que el perjuicio ocurra. Del doctrinante mencionado extraemos el siguiente definición: 
...con lo que se quiere significar que se anticipan a la decisión definitiva para proteger el derecho, que pueden practicarse sin audiencia del demandado que las soporta, y que su decreto, en sí mismo considerado, no traduce un juzgamiento ni que se otorgue razón al peticionario. (Álvarez, 2014, p.32)

Y se resalta la parte última de su definición, pues esa es la hipótesis que se pretende confirmar a lo largo del desarrollo de esta temática, pese a detractores que consideran que aquel que soporta la carga de la medida ya es culpable dentro del proceso en la cual se encuentra inmerso, como si la medida cautelar fuera una pre-sentencia judicial, lo cual no es cierto de ninguna manera.

En nuestro sistema procesal colombiano, el Código General del Proceso en el Libro Cuarto, Título I, Capítulo I contiene todo lo relacionado con las medidas cautelares, su clasificación dependiendo de la finalidad que se persigue y el tipo de procesos en el cual se hará efectiva la medida. Lo que nos lleva a revisar someramente las clases de medidas cautelares las cuales se dividen en:

a. Personales: recaen sobre personas.

b. Patrimoniales: recaen sobre el patrimonio.

c. Sobre actos jurídicos

d. Nominadas o típicas: previstas en la ley.

e. Innominadas o atípicas: no contempladas en la ley.

f. Innovativas: producen una alteración en la situación jurídica de las partes.

Las anteriores serán finalmente aplicadas teniendo en cuenta 1) la solicitud de las partes en el proceso en curso o bien la oficiosidad del juez, 2) la coherencia entre éstas y el fin último que se persigue con la medida, 3) la premura o urgencia de la medida, 4) la apariencia de buen derecho y 5) tener en cuenta el peligro de mora judicial en que se cae si no se decreta a tiempo.

En la Ley 1564 de 2012 (Código General del Proceso) en los inicios del Libro Cuarto dedicado a las medidas cautelares, más puntualmente en el artículo 589 abrió la puerta a que se decretaran medidas de cautela en otro tipo de procesos tales como procesos por propiedad intelectual, actos de competencia desleal y los demás casos que exprese la ley, cuando se trate de pruebas extraprocesales.

Llegamos al punto que nos interesa tocar, ya que es la posibilidad de concebir la práctica de medidas cautelares aún sin iniciarse formalmente un proceso judicial, siempre y cuando este cumpla con todos los requisitos exigidos por la ley, y que se harán valederas ante cualquier autoridad jurisdiccional. 
Tratándose de competencia desleal, la cual se encuentra regulada en la Ley 256 de 1996 en su artículo 20 contempla, dentro de las acciones tendientes a contrarrestar actos que se consideren en contra de la libre competencia comercial la de acción preventiva o de prohibición que señala lo siguiente:

ARTículO 20. ACCIONES. Contra los actos de competencia desleal podrán interponerse las siguientes acciones:

1. ACCIÓN DECLARATIVA Y DE CONDENA: el afectado por actos de competencia desleal tendrá acción para que se declare judicialmente la ilegalidad de los actos realizados y en consecuencia, se le ordene al infractor remover los efectos producidos por dichos actos e indemnizar los perjuicios causados al demandante. El demandante podrá solicitar en cualquier momento del proceso, que se practiquen las medidas cautelares consagradas en el artículo 31 de la presente Ley.

De la cita se resalta que, ya la norma en vigencia en 1996 dió vía libre para que las medidas cautelares pudieran hacer efecto en este tipo de procesos cuando se tenga plena convicción de la vulneración de un derecho que causa un perjuicio peligroso para la parte que la soporta, permiso que fue ampliamente otorgado más tarde en el artículo 589 del Código General del Proceso.

Álvarez Gómez (2014) expresa claramente los motivos por los cuales se incluyen las medidas cautelares en los procesos por competencia desleal señalando:

En materia de competencia desleal, por ejemplo, la acción declarativa y de condena por la pérfida participación en el mercado tiene el propósito de obtener un pronunciamiento sobre la ilegalidad de los actos realizados, la remoción de los efectos producidos y la consecuente indemnización de los perjuicios causados al demandante. Empero, aunque es en la sentencia en la que el juez se pronunciará en forma definitiva sobre prohibirle al demandado realizar determinados actos que juzgará desleales, bien puede el demandante solicitar con su demanda que, como medida cautelar, se ordene la cesación provisional del acto respectivo (...) (p.34)

Así las cosas, el motivo de incluir la cautela a esta clase de procesos, se debe a que la razón última es obtener una condena por actos de competencia desleal que influyen directamente en el mercado causándole graves daños de carácter patrimonial al afectado, poniéndose en juego no sólo el aspecto económico sino también la estabilidad comercial, el buen nombre, el flujo y mantenimiento de la clientela entre otros aspectos que preocupan a los comerciantes, empresas y demás involucrados en la dinámica comercial.

Vistas las cautelas a groso modo y de manera general, el eje temático corresponde a las medidas cautelares aplicadas a los procesos por competencia desleal por ser de carácter especial por las repercusiones que estas tienen en las partes y los daños patrimoniales que se generan, por tanto, es menester que se examine en primer lugar, rasgos generales de ese proceso, y en segundo lugar, de qué forma son aplicadas las medidas a estos procesos. 


\section{Las medidas cautelares en los Procesos por competencia desleal}

Para contextualizar sobre este tipo de procesos, comenzamos por decir que en materia comercial la Superintendencia de Industria y Comercio -SIC- (como se citó en Delgado Peña, 2015) ha definido la competencia como "el conjunto de esfuerzos que desarrollan los agentes económicos que, actuando independientemente, rivalizan buscando la participación efectiva de sus bienes y servicios en un mercado determinado" (p.96). En tratándose de actos contrarios de competencia, llamado competencia desleal "cuando resulte contrario a las sanas costumbres mercantiles, al principio de la buena fe comercial, o bien cuando esté encaminado a afectar o afecte la libertad de decisión del comprador o consumidor, o el funcionamiento concurrencial del mercado" (Delgado Peña, 2015, p.96)

Para Delgado Peña (2015) no es suficiente que se realicen actos que se entienden contrarios a la competencia, hace falta que concurran los demás requisitos tales como: 1) Sujeto activo y/o pasivo pueden tener o no la calidad de demandante, 2) El acto debe generarse dentro del mercado, 3) El acto debe ser concurrencial y exteriorizado, 4) El acto debe ser contrario a la buena fe comercial, 5) Que el acto sea indebido y se hubieron empleados los medios idóneos para tal fin, y 6) Que hayan existido formas de evitar los actos desleales.

En definitiva, los procesos de competencia desleal tienen como objetivo frenar los actos que se consideran van en detrimento de la sana competencia económica entre oferentes de bienes y servicios o anticiparse a posibles daños que se puedan causar con la ejecución de dichos actos.

El antecedente normativo que vincula la propiedad industrial y los actos de competencia desleal, lo encontramos en el Convenio de París para la propiedad industrial ratificado por Colombia por medio de la Ley 178 de 1994, en el cual en su artículo 10bis lo dedica a definir la competencia desleal así:

ARTICULO 10- bis- [COMPETENCIA DESLEAL].

1. Los países de la Unión están obligados a asegurar a los nacionales de los países de la Unión una protección eficaz contra la competencia desleal.

2. Constituye acto de competencia desleal todo acto de competencia contrario a los usos honestos en materia industrial o comercial.

3. En particular deberán prohibirse:

1) Cualquier acto capaz de crear una confusión, por cualquier medio que sea, respecto del establecimiento, los productos o la actividad industrial o comercial de un competidor; 
2) Las aseveraciones falsas, en el ejercicio del comercio, capaces de desacreditar el establecimiento, los productos o la actividad industrial o comercial de un competidor;

3) Las indicaciones o aseveraciones cuyo empleo, en el ejercicio del comercio, pudieren inducir al público a error sobre la naturaleza, el modo de fabricación, las características, la aptitud en el empleo o la cantidad de los productos.

Más tarde, se expidió la Ley de Competencia Desleal (Ley 256 de 1996) en el cual se encuentran especificados los actos atentativos de la competencia, que son:

- Actos de desviación de clientela. (Art. 8)

- Actos de desorganización. (Art. 9)

○ Actos de confusión. (Art. 10)

- Actos de engaños. (Art. 11)

- Actos de descrédito. (Art. 12)

- Actos de comparación. (Art. 13)

- Actos de imitación. (Art. 14)

○ Explotación de la reputación ajena. (Art. 15)

○ Violación de secretos. (Art. 16)

- Inducción a la ruptura contractual. (Art. 17)

○ Violación de normas. (Art. 18)

- Pactos desleales de exclusividad. (Art. 19)

Esta normativa plantea dos acciones por las cuales se puede contrarrestar los efectos de los actos arriba mencionados y son: 1) la acción declarativa y de condena; cuando se pretende mitigar el impacto causado por la ejecución del acto de competencia desleal y la indemnización de los perjuicios ocasionados y 2) la acción preventiva o de prohibición, que es la posibilidad del que se cree puede resultar afectado con un acto de competencia desleal para solicitar su protección previniéndolo o prohibiéndolo.

Los afectados con estas conductas contrarias a la libre y sana competencia económica son los agentes económicos que integran el mercado, además, desde la Convención de Paris se estableció quienes pueden ser los interesados en reprimir o frustrar actos 
contradictorios a las prácticas normales de competencia en la industria. En el artículo 10ter. de este tratado señala:

ARTICULO 10 ter. [MARCAS, NOMBRES COMERCIALES, INDICACIONES FALSAS, COMPETENCIA DESLEAL: RECURSOS LEGALES; DERECHO A PROCEDER JUDICIALMENTE].

(...) 2. Se comprometen, además, a prever medidas que permitan a los sindicatos y asociaciones de representantes de los industriales, productores o comerciantes interesados y cuya existencia no sea contraria a las leyes de sus países, proceder judicialmente o ante las autoridades administrativas, para la represión de los actos previstos por los artículos 9, 10 y 10bis, en la medida en que la ley del país donde la protección se reclama lo permita a los sindicatos y a las asociaciones de este país.

Estos sujetos adoptan el nombre de legitimados en la causa por activa al ser los que pongan en movimiento el aparato jurisdiccional, y los receptores, aquellos gestadores de la conducta desviada, son los legitimados en la causa por pasiva, ambas figuras consagradas en los artículos 21 y 22 de la Ley 256 de 1996.

Se debe mencionar además, que los procesos por competencia desleal se pueden seguir por dos vías jurisdiccionales habilitadas por la ley para su conocimiento. El Código General del Proceso es preciso a la hora de fijar la competencia del juez conocedor de la litis otorgándole la potestad, primero, a los jueces civiles del circuito en su artículo 20 que reza:

Artículo 20. Competencia de los jueces civiles del circuito en primera instancia. Los jueces civiles del circuito conocen en primera instancia de los siguientes asuntos: (...)

3. De los de competencia desleal, sin perjuicio de las funciones jurisdiccionales atribuidas a las autoridades administrativas.

Y más adelante, le concede la facultad de conocer a la Superintendencia de Industria y Comercio - SIC- Ios casos de competencia desleal dentro de los asuntos conocedores de las autoridades administrativas que ejercen funciones jurisdiccionales, consagrado en el artículo 24 del mismo estatuto así:

Artículo 24. Ejercicio de funciones jurisdiccionales por autoridades administrativas. Las autoridades administrativas a que se refiere este artículo ejercerán funciones jurisdiccionales conforme a las siguientes reglas:

1. La Superintendencia de Industria y Comercio en los procesos que versen sobre:

a) Violación a los derechos de los consumidores establecidos en el Estatuto del Consumidor.

b) Violación a las normas relativas a la competencia desleal. 
Esta potestad recopilada por el CGP, ya había sido concedida en los artículos 143 y 144 de la Ley 446 de 1998, por el cual otorgaba a la SIC la función de conocer asuntos sobre competencia desleal y facultaba a la misma en la investigación de estos asuntos a seguir el trámite previsto para las infracciones al régimen de promoción de competencia y prácticas restrictivas adoptando las medidas cautelares que hubiere lugar, respectivamente. Dichas disposiciones que fueron demandadas por inconstitucionalidad pero que, finalmente, en sentencia C-649 del 20 de junio de 2001 la Corte Constitucional la declaró exequible ratificando la competencia a prevención de la SIC y jueces de la república para conocer de estos temas.

Así mismo, se halla otra competencia que se atribuye al que conozca de las prácticas de medidas cautelares en pruebas extraprocesales en los asuntos de competencia desleal y propiedad intelectual del artículo 589 del CGP antes mencionado, en el que conocerá todo lo relacionado con las medidas hasta la presentación de la demanda, una vez esta sea radicada, el juez de conocimiento será el único competente para adoptarlas.

Dicho lo anterior, es preciso profundizar sobre la aplicación de las medidas cautelares en los procesos seguidos por actos de competencia desleal siendo este regulado por el artículo 31 de la Ley 256 de 1996, el cual en su inciso primero manifiesta que de comprobarse el acto la inminencia del mismo el juez podrá decretar la medida.

Pero para que una medida cautelar de las contempladas en la ley o aquellas innominadas pueda prosperar es necesario que se acredite el cumplimiento de los presupuestos como:

(i) el accionante se encuentre legitimado o autorizado para demandar las medidas, para lo cual deberá acreditar su participación en el mercado y la afectación, actual o potencial, de sus intereses económicos como consecuencia de los actos que denuncia; y del otro, (ii) que se aporte prueba suficiente, aunque ella tuviere la calidad de sumaria (...). (Agudelo, Vega \& Villegas, 2013, p.25)

Se reitera que, para los procesos por competencia desleal son válidos las medidas cautelares de carácter innominadas que, para que sean decretadas tendrán que cumplir con una serie de requerimientos para que se consideren viables en este tipo de procesos declarativos, entre esos tenemos:

Legitimación o interés para actuar de las partes - la existencia de la amenaza - la vulneración de un derecho - la apariencia de buen derecho - la necesidad, efectividad y proporcionalidad de la medida - la mayor conveniencia: no necesariamente la que la parte solicite, puede solicitar una menos gravosa e inclusive diferente - establecer el alcance y determinar su duración - disponer para modificarla, sustituirla o que cese la medida cautelar. (Trujillo Londoño, 2014, p.180)

Una vez el accionante que crea se le ha vulnerado un derecho causándole un perjuicio como consecuencia de una acción de competencia desleal podrá hacer uso de la 
solicitud de medidas cautelares en tres momentos:

1. Previa a la presentación de la demanda.

2. En el curso de la demanda.

3. Con la presentación de la demanda.

En el primer evento, es posible gracias al amparo del artículo 589 del CGP que da la venia para practicar medidas cautelares a pruebas extraprocesales en los casos de competencia desleal, lo que sin lugar a dudas, es una importante garantía para todo aquel que se siente transgredido en el ámbito comercial y que aporte el material probatorio suficiente para formar esa apariencia de buen derecho a su favor.

En el segundo caso, por ser un proceso declarativo, porque busca la declaración de un derecho, en este caso, la existencia o no de la perpetración de un acto contrario a la competencia y la consecuente indemnización por los perjuicios causados, podrá el juez decretar una medida cautelar innominada en el momento que lo considere necesario.

Y en el tercer evento, en el mismo momento de radicación de la demanda ante la autoridad jurisdiccional va inmerso el escrito de medidas cautelares, en la cual el juzgador deberá pronunciarse a más tardar al día siguiente del reparto o la presentación de la solicitud según lo dispuesto en el artículo 588 del Código General del Proceso.

A propósito de las medidas cautelares en los procesos declarativos, y cuando la acción que se persiga en estos procesos por competencia desleal sea declarativo y de condena, en el literal b del numeral $1^{\circ}$ del 590 del CGP señala que procederán las medidas cautelares de inscripción de la demanda, embargo y secuestro de bienes cuando la finalidad sea perseguir el pago de perjuicios causados por responsabilidad extra o contractual, que se hará efectivo en los siguientes términos:

Artículo 590. Medidas cautelares en procesos declarativos. En los procesos declarativos se aplicarán las siguientes reglas para la solicitud, decreto, práctica, modificación, sustitución o revocatoria de las medidas cautelares: (...)

b) La inscripción de la demanda sobre bienes sujetos a registro que sean de propiedad del demandado, cuando en el proceso se persiga el pago de perjuicios provenientes de responsabilidad civil contractual o extracontractual.

Si la sentencia de primera instancia es favorable al demandante, a petición de este el juez ordenará el embargo y secuestro de los bienes afectados con la inscripción de la demanda, y de los que se denuncien como de propiedad del demandado, en cantidad suficiente para el cumplimiento de aquella. 
Punto para destacar en la procedencia de las medidas cautelares, es que cuando se pretende el decreto y práctica de las mismas dentro de un proceso declarativo el parágrafo primero de la norma en cita establece que "en todo proceso y ante cualquier jurisdicción, cuando se solicite la práctica de medidas cautelares se podrá acudir directamente al juez, sin necesidad de agotar la conciliación prejudicial como requisito de procedibilidad." (Código General del Proceso, Art. 590). Por tanto, la conciliación no se hace exigible cuando se presenta la solicitud de una medida cautelar, sin perjuicio de que la parte quiera agotarlo.

La Superintendencia de Industria y Comercio se ha venido pronunciando en los casos de competencia desleal que por medio de sus fallos ha marcado pautas en cuanto al decreto y práctica de medidas cautelares y edificando conceptos cruciales para que la procedencia de las mismas en el curso de estos procesos.

Uno de los ejemplos a exponer es la Resolución No. 16158 del 19 de julio de 2004 extraida del compendio de doctrina y jurisprudencia de competencia desleal de la SIC, la cual esta entidad se pronunció frente la legitimación del actor para solicitar medidas cautelares manifestando que para determinar dicha legitimación era necesario tener claro que se entiende participación en el mercado concluyendo que:

En este sentido, el concepto de participación en el mercado es un elemento determinante para establecer si la actora es, o puede llegar a ser, afectada por los actos que cuestiona como desleales. Una persona participa en un mercado, cuando toma parte del mismo, es decir, cuando concurre a él ofreciendo bienes o servicios, a fin de disputar una clientela. En consecuencia, el mercado no es un lugar abstracto e ilimitado, sino que frente a cada situación requiere ser precisado, teniendo en cuenta los factores que en cada caso particular toman en consideración los clientes o compradores para elegir entre las diferentes ofertas o alternativas que son puestas a su elección. (SIC, 2006, p.141)

Por lo anterior se infiere que, si el oferente de un producto no se encuentra realmente "ofreciendo" sus productos a la demanda, no puede considerarse que es un agente económico del mercado, y por consiguiente, no puede hacerse acreedor de la acción cuando crea que se están ejecutando actos contrarios a la competencia y mucho menos para solicitar medidas cautelares.

Otro aspecto a tener en cuenta, es que el espectro industrial se puede limitar dependiendo de qué tanto el oferente pusiera sus productos a disposición del mercado, de esa manera se puede comprobar su participación en el mismo y si resulta o no afectado con actuaciones desleales en materia de competencia.

En otro de los pronunciamientos que marcan precedente referente a los criterios a tener en cuenta por parte de la Superintendencia de Industria y Comercio o el juez para decretar medidas cautelares en los procesos por competencia desleal es el auto No. 
05046 del 27 de octubre de 2005 en la que ha sido claro en enfatizar sobre la actitud que debe asumir el juzgador al momento de decidir sobre la imposición de una cautela.

Se recalca en este auto que el juzgador al momento de determinar si impone o no una medida cautelar debe valorar de acuerdo a las reglas de la sana crítica las pruebas sumarias que el actor le presente, que no por ser sencillas, deben perder la rigurosidad con debe ser analizadas para establecer, finalmente, si existe o no un acto inminente que cause un detrimento en la libre competencia o en peligro de estarlo.

De la comprobación de la realización de actos de competencia desleal o de su inminencia la SIC (2006) ha dicho lo siguiente:

\begin{abstract}
Estima el despacho que si bien es posible solicitar el decreto de cautelas con pruebas sumarias de la comprobación o inminencia de actos de competencia alegados como desleales, su evaluación no supone que el juzgador deba mantener una posición pasiva y acceder a la solicitud por el solo aporte de pruebas sumarias de la realización de conductas cuya adecuación a los supuestos de deslealtad corresponde al juicio del solicitante. (p.183)
\end{abstract}

Dado el caso de petición de decreto de medida cautelar anexando pruebas sumarias, el juez no puede vendarse y creer ciegamente en ellas, pues su decisión debe estar soportada por argumentos jurídicos que le permitan convencerse y convencer a las partes que decretar una cautela obedece a circunstancias extremas que, de no practicarse, se corre el riesgo de un perjuicio mayor.

Por lo que toma importancia el valor de la certeza, el juzgador debe tener plena seguridad de que los actos que se están realizando son contrarios a la competencia, comprobarlos por todos los medios y luego si estos causan un peligro inminente. Dicha regla debe ser aplicada para todos los actos de competencia desleal contemplados en la Ley 256 de 1996.

Así lo ha detallado la SIC en el concepto del 16 de marzo de 2016 manifestando:

[...]no sólo se requiere que quien solicite las medidas cautelares esté legitimado para realizar esta solicitud -es decir, que participe en el mercado o demuestre su intención por participar en el mismo, y que sus intereses económicos resulten perjudicados o amenazados por los actos de competencia desleal- sino que, además, es necesario que se aporte prueba, si quiera sumaria, que permita tener por comprobada la realización de un acto de competencia desleal o su inminencia. Además de lo anterior, debe darse cumplimiento a los ámbitos objetivo, subjetivo y territorial contenidos en la Ley 256 de 1996. (p.11)

Que se entienda por prueba sumaria, aquella que, por más simple que sea, sirva de medio para probar que ha existido un acto desleal o contrario a la sana competencia y que el daño que está causando sea inminente, para ello, el conocedor del asunto en disputa constituirá caución por tratarse de un proceso declarativo, con la libertad de imponer aquella que considere razonable en el caso de estudio. 
Otro de los valores presentes y del cual el juzgador no puede desprenderse es la objetividad, sin dejarse de llevar por criterios personales o pasiones ajenas al interés de las partes y del proceso, y para el caso en particular, el decreto y práctica de una medida cautelar este debe estar revestido de ella, ya que está en juego las partes y hasta terceros.

De manera que, se reitera además de los valores mencionados, que el juez tenga la capacidad de ver la apariencia de buen derecho para darle seguridad a su decisión sobre la medida cautelar solicitada por una de las partes, pero a su vez surgen interrogantes al ser decretada y practicada esa medida tales como que su imposición constituye prejuzgamiento para la parte que la soporta, como si se tratase de una sentencia anticipada, lo que desdibuja la función de la justicia y de las autoridades jurisdiccionales dedicados a dirimir estos conflictos.

Constituye o no prejuzgamiento al decretar medida cautelar dentro de los procesos por competencia.

El decreto de una medida cautelar desde sus orígenes ha generado incertidumbre sobre sus reales intenciones, es decir, si sólo busca proteger los derechos que en apariencia son vulnerados o bien, tiene oculto la finalidad de "prejuzgar" dentro de un proceso, cercenado así los derechos constitucionales de defensa y contradicción.

Tratadistas y doctrinantes no coinciden en sus posiciones, puesto que unos consideran que permitir una medida cautelar no constituye prejuzgamiento y/o decisión anticipada del proceso, sino que corresponde a un seguro en caso de que la parte a quien se le otorgó a su favor venza en la litis. Otros por el contrario, aseguran que no es tan benéfico que una de las partes soporte la carga de una medida cautelar, porque se entendería que él es el infractor y debe garantizar el resarcimiento de los daños con dicha medida, lo que impide una real y verdadera defensa de sus derechos.

Para el doctrinante Sandoval Gutiérrez (2016) estudiar sobre la inminencia de la realización de un acto atentativo de competencia, termina por resolver directamente el núcleo del proceso. En sus palabras señala:

Pues bien, comprobar la realización de un acto de competencia desleal supone un análisis fáctico
y probatorio que conduzca a la verificación de la ejecución de una de las conductas que la Ley
256 de 1996 considera desleales. Ese análisis y verificación es, en últimas, un estudio sobre
el fondo del proceso, sobre la cuestión litigiosa que se debate y sobre lo que motivó la puesta
en funcionamiento de las funciones jurisdiccionales del Estado, sólo que la decisión tendrá un
carácter provisional. (p.169)

De lo citado se extrae, que los argumentos que son utilizados por el juzgador para decretar una medida cautelar en estos procesos, teniendo en cuenta la comprobación 
del mismo, coinciden con los expuestos en la decisión dentro del proceso, por lo que, se considera resuelve el fondo del objeto de este.Por tanto, ya existe un pronunciamiento previo sobre el motivo de la litis mucho antes del fallo.

Siguiendo en el mismo enfoque, el autor manifiesta que el juzgador que conoce de una medida cautelar y accede a ella, valorando los hechos y las pruebas que el interesado presenta, no puede luego desarraigarse de su decisión dictando una sentencia contrario al sustento argumentativo que esgrimió en el primer pronunciamiento.

El interrogante de Sandoval Gutiérrez (2016) gira entorno a que:

Si dentro de las pruebas recaudadas en la etapa probatoria no existe ninguna que sea contundente para que se profiera una decisión diferente a la que se tomó al momento de resolver sobre la solicitud de medidas cautelares, ¿debe el juez proferir la decisión definitiva en el mismo sentido que la provisional? (p.170).

A lo que llega a la conclusión el autor que es un error que el juez tome una decisión distinta de la inicial provisional, en virtud de que, si llegó a ella obedeció a la vista con lupas de la situación fática y probatoria mostrada por el interesado y si se desvía de sus primeros lineamientos estaría incurriendo en faltas graves.

Esos errores en los que el juez incurre según Sandoval Gutiérrez (2016) se resumen así:

1. Violación de la seguridad jurídica, porque varió el nivel de certeza sobre hechos y pruebas lo que genera poca credibilidad en el decreto de la medida cautelar.

2. Violación del precedente horizontal, porque contaría sus propias decisiones.

3. Violación al principio de buena fe y confianza legítima, pues la labor del administrador de justicia es brindar confianza a quienes acuden a él.

4. Error en la actividad jurisdiccional, que se considera un mal ejercicio de sus funciones de juzgador.

Lo anterior, demuestra que la autoridad jurisdiccional no goza de coherencia en sus decisiones y que por tanto, puede provocar un malestar entre las partes dentro del proceso al variar su posición y terminar fallando algo muy distinto a lo dicho en la imposición de la medida cautelar, pero la realidad no es esa.

Dicho en líneas anteriores, dos de las características principales de las medidas cautelares es, primero, la provisionalidad, no es un gravamen que se perpetúe en el tiempo o es un castigo desde antes de decidir sobre la litis, es una garantía que el legislador ha propuesto para garantizar el cumplimiento de una obligación o frenar los efectos de actos contrarios a la competencia o simplemente para prevenirlos en caso de que se encuentre evidencia de un eventual daño pero al que se le decretó la medida no puede sentirse victorioso y no puede descuidar su función de probar dentro del proceso. 
Ahora bien, hay que sacarse de la mente que el hecho de que se haya decretado una medida cautelar se le eximió al actor de la carga de probar porque sumariamente demostró la vulneración de un derecho o la generación de una acto en contra de libre competencia, en este caso, pero el juez en ese momento procesal lo que vislumbra es el fumus bonis iuris o apariencia de buen derecho, la segunda de las características y quizá la más importante, puesto que el juez debe observar el grado de verosimilitud frente a hechos y pruebas o dicho de otro modo:

La apariencia de bueno derecho, o también conocido como fumus bonis iuris, hace referencia al juicio o reflexión hecho por el Juez en sede cautelar para deducir cuales son las probabilidades que existen, en cuanto a la posibilidad de que se le declare al demandante, quien solicita la cautela, el derecho a su favor en la providencia final, sin que esto signifique un prejuzgamiento de la parte; por ello se habla de probabilidad o verosimilitud del derecho, así mismo Calamandrei (1945) expresa que "este principio se refiere a la investigación que se realiza sobre el derecho, es decir que el conocimiento cautelar se limita, en todos los casos, a un juicio de probabilidades y verosimilitud." (p. 77) (Cuellar \& Villamizar (2015), p.97)

De lo expuesto se resalta que, lo que debe primar para el juzgador es el grado de certeza producto de un análisis de probabilidades sobre una eventual vulneración o perturbación de un derecho como consecuencia de una actuación desviada de competencia, por tanto, el proceso debe continuar surtiendo las etapas del caso para finalmente determinar si es favorable o no a las pretensiones del demandante.

Si bien es cierto que, en materia de competencia desleal, el artículo 31 de la Ley 256 de 1996 señala que para aplicar una medida cautelar se debe comprobar la realización de conductas contrarias a la competencia, estas deben ser decretadas de carácter provisional, no definitivas, ni absolutas. El contrario a lo largo del proceso puede probar los hechos de que se le acusa y puede incluso, cambiar la percepción que tenga el juez de la historia procesal planteada por el actor, logrando que prosperen sus excepciones.

Al ser provisional la esencia de las medidas cautelares no debe viciar la construcción de la providencia final, que "la provisoriedad de las providencias cautelares no tiene, en cambio, conexión con el modo de formación de la providencia." (Calamandrei, 1984, p.39). Así las cosas, las medidas son una garantía para el cumplimiento del objeto procesal, dicho en palabras de Calamandrei (1984)

La providencia cautelar tiene efectos provisorios no porque (o no necesariamente porque) la cognición sobre la cual se basa sea menos plena que la ordinaria y deba, por consiguiente ir acompañada de una menor estabilidad de efectos, sino porque la relación que la providencia cautelar constituye está, por su naturaleza, destinada a agotarse, ya que su finalidad habrá quedado lograda en el momento en que se produzca la providencia sobre el mérito de la controversia. (p.40). 
El planteamiento del citado autor es lo que el tratadista en contra, Sandoval Gutiérrez, pretendía demostrar,que en el caso de las providencias que decretan medidas cautelares que al igual que la sentencia final, se encuentran nutridas de sustento jurídico y conceptual que le permita soportar su decisión, tienen la particularidad de tener fin, de agotarse, de perecer una vez finalice el proceso, pero de ninguna manera dirimir el conflicto a tratar.

De afirmarse que, las medidas cautelares y sus diversas modalidades son una forma de definir un proceso va en contra de su propio concepto y la finalidad para las cuales fueron creadas. En otras palabras:

La definición de las medidas cautelares innominadas y anticipatorias, no involucra en ningún momento una forma de dar un prejuzgamiento al proceso. Por el contrario el juez en la trayectoria del juicio de acuerdo a las pruebas presentadas va decidiendo el fallo sin que ello se aprecie en un prejuzgamiento o fallo anticipado.(Contreras, 2015, p.24).

Así las cosas, lo que define a un proceso en sí son las pruebas que, realmente, acrediten o no la vulnerabilidad de un derecho, que para el caso de la competencia desleal, atente contra el curso normal de los agentes del mercado.

En materia de competencia desleal, el tema del prejuzgamiento al acceder a una medida cautelar ha sido decantado por la autoridad jurisdiccional que puede conocer de estos procesos, la Superintendencia de Industria y Comercio, quien en sus fallos ha tratado de establecer la línea que divide la resolución de medidas cautelares y las providencias que deciden de fondo el asunto planteado por las partes.

Así, en el auto No. 05046 del 27 de octubre del 2000, la SIC (2006) intenta explicarle al actor el concepto de "prejuzgar" partiendo de la base de que el juzgador conoce con antelación los hechos y las pruebas que lo acompañan para luego expedir un pronunciamiento sobre ello, sin necesidad de que surtan todas las etapas procesales, una sentencia anticipada. Concepto que explica de la siguiente manera: "La acción de prejuzgar un asunto supone el conocimiento previo del objeto de juicio anticipado (...). Para establecer si se prejuzgó el fondo de un asunto, hay que determinar qué tipo de solicitud presentó el actor." (p.182)

Así mismo, continua la SIC (2006) señalando que se debe distinguir entre una solicitud de medida cautelar y la presentación de una demanda por competencia desleal, teniendo en cuenta que, la primera es anterior a la segunda. La SIC ha dicho que:

En el caso estudiado, el peticionario no presentó una demanda principal de competencia desleal, sino exclusivamente una solicitud de medidas cautelares. Ello implica, tal como se hizo en la providencia recurrida, que la autoridad judicial analice la procedencia o improcedencia de esa solicitud a la luz de la norma que consagra su viabilidad (artículo 31 de la Ley 256 de 1996), lo que a su vez conlleva forzosamente a que manifieste su grado de convencimiento sobre la 
comprobación de la realización de actos desleales o su inminencia, de acuerdo con los hechos planteados en la solicitud y a los fundamentos de derecho y pruebas que la soportan. (p.182)

Y por último concluye la SIC (2006) diciendo:

Enseña la jurisprudencia que atendiendo a la finalidad preventiva y provisional de las medidas cautelares, en el momento en que se hacen necesarias no se juzga ni se prejuzga sobre el derecho de quien las pide, por lo cual, ni el decreto ni la denegación de medidas cautelares equivalen a un prejuzgamiento o presentencia, ni vulneran el derecho de defensa o del debido proceso del actor o del accionado, pues nada obsta para que en la actuación probatoria en un eventual proceso principal, estos puedan demostrar una situación contraria a la inicial pudiendo modificar el convencimiento del despacho. (p.182)

La postura de la SIC frente al tema de considerar que resolver una solicitud de medida cautelar es una presentencia no es posible, es valedero en razón de que, el proceso trazado por la Ley 256 de 1996 no contempla ninguna alternativa que permita inferir que el acceder a una medida cautelar tenga necesariamente que ser compatible con un prejuzgamiento, puesto que el que soporta la medida tiene todas las vías procesales que le otorga la Constitución Política, la ley especial de competencia, otras normas análogas, la jurisprudencia y la doctrina y el material probatorio con que cuenta para desdibujar de la memoria del juzgador cualquier imagen que se haya podido hacer éste con la solicitud de la medida.

De manera que, dar vía libre a la idea de que las medidas cautelares fueron pensadas con la intención de prejuzgar dentro de un proceso judicial, en este caso, aquellos que el objeto procesal sea la competencia desleal “...se desvía totalmente de la finalidad que tienen este tipo de medidas, pues lo único que buscan es que a lo largo del proceso el juez proteja el derecho en litigio de la mejor forma posible"(Bolívar Mesa, s.f. p.18).

Caso puntual se puede evidenciar en la Resolución No. 7335 de 22 de febrero de 2016 en el que la SIC niega una solicitud de medida cautelar. Dentro de los argumentos generales, es importante destacar que esta autoridad jurisdiccional sigue manteniendo una posición precisa respecto al decreto de las medidas cautelares manifestando que el juzgador debe analizar además de una conducta anticompetitiva y las pruebas que lo demuestran, evalua el peligro que se presenta en caso de ser decretada, en sus palabras, el riesgo de efectividad.

Ahora bien, en lo que atañe al prejuzgamiento que podría constituir al decretarse una medida cautelar en los casos de competencia desleal ha dicho:

Resulta importante resaltar que esta facultad cautelar de la Superintendencia de Industria y Comercio consiste en una intervención a priori de la Autoridad en el mercado, con miras a blindar su eventual decisión de una posible inocuidad. Dicha intervención no constituye prejuzgamiento alguno sobre las indagaciones que simultáneamente puede estar adelantando la Delegatura para la Protección de la Competencia respecto de las conductas sub examine. (Res. No. 7335 de 2016, p.2) 
Así las cosas, la SIC distingue la investigación como consecuencia de un indicio de caso de competencia desleal y la decisión sobre medidas cautelares que es anterior y que requiere que se cumplan ciertos parámetros valorando siempre el riesgo de efectividad, con el fin de "evitar que la decisión final sobre la materia sea nugatoria."(Res. No. 7335 de 2016, p.3)

En el proceso estudiado, la solicitud es negada porque se encontró que no demostró el peligro de mora, la apariencia de buen derecho y la proporcionalidad, esto último tiene que ver con la carga que debe soportar el sujeto pasivo y el beneficio que le trae al activo, por cuanto resulto improcedente para los intereses del actor.

Resulta pertinente para el asunto bajo estudio lo dicho por la SIC con relación a que pone los limites en cuanto a la forma como debe tratarse una solicitud de medida cautelar y una investigación propiamente dicha. En la resolución 7335(2016) la SIC refiriéndose a esa distinción resalta que la investigación puede iniciarse con indicios y que hasta ese momento solo vincula a las partes involucradas, mientras que, la solicitud de medida cautelar se resuelve con pruebas contundentes de la presencia del daño o el peligro de ocurrencia del mismo.

\section{Conclusiones}

De todo lo que se ha expuesto se hace ineludible mencionar que las medidas cautelares son de las más valiosas herramientas que ha podido crear el legislador como forma de garantía del cumplimiento de una obligación, proteger un derecho que ya ha sido violado o prevenir que sea vulnerado y en el caso de los asuntos por competencia desleal, toma gran relevancia ya que de no tomarse los correctivos en el momento justo no sólo se ven afectadas las partes involucradas sino, inclusive, terceros ajenos al conflicto.

La provisionalidad de las medidas cautelares deja de ser una característica de éstas para convertirse en su esencia misma junto con la apariencia de buen derecho, toda vez que ambos coinciden en que no contienen verdades absolutas, es decir, pueden agotarse, o desaparecer dependiendo de cómo se vaya desenvolviendo el proceso.

Lo dispuesto en el artículo 31 de la Ley 256 de 1996 sobre las medidas cautelares, para algunos tiende a generar dudas en cuanto a la rigurosidad con que se exige que se compruebe la realización de los actos de competencia desleal y la inminencia de la medida pero es que esos precisamente deben ser los presupuesto exigidos para que la medida cautelar no sea tomada a la ligera sino que por el contrario, ésta sea decretada producto de un análisis crítico por parte del juzgador con miras a la protección de quien se vea afectado. 
Se entiende también que, existe una delgada línea entre el hermetismo y la severidad con que deben ser cumplidos los requisitos de una medida cautelar y si su decisión sobre la misma implica un prejuzgamiento, pero no se debe dejar de lado que el proceso por el cual se resuelven estos casos de competencia debe surtirse para que dicho fallo pueda pasar a cosa juzgada, por lo que una providencia cautelar no dirime ni pone fin a un conflicto en que se deben escuchar ambas partes, por tal motivo, no es equivocado decir que no se están coartando las libertades de las partes para interponer su defensa y contradecir lo dicho por el solicitante.

Ahora bien, decir que el juzgador traiciona sus propios lineamientos al variar su posición desde la providencia que decide sobre una medida cautelar hasta la sentencia definitiva es errado, pues sus fallos deben tener el sustento jurídico y sobre todo probatorio que le proporcione el convencimiento para definir un litigio por competencia, otorgándole la razón a quien probatoriamente lo probo dentro del proceso y dictando los correctivos que haya lugar. Sus pronunciamientos anteriores (extraprocesales y procesales en cuanto a medidas cautelares) si bien no lo atan tampoco pierden el peso del efecto ni el impacto que causa su práctica.

\section{REFERENCIAS Bibliográficas}

Agudelo, Y., Vega, J. \& Villegas, J. (2013). El ejercicio de la acción de competencia desleal en materia jurisdiccional. Pontificia Universidad Javeriana, Bogotá D.C., Colombia. Recuperado de: https://repository.javeriana.edu.co/bitstream/ handle/10554/14882/AgudeloGuioYuranyAndrea2013.pdf?sequence=1\&isAllowed=y

Álvarez, M. (2014). Las medidas cautelares en el Código General del Proceso. Escuela Judicial Rodrigo Lara Bonilla. 1-151. Recuperado de https://docs.wixstatic.com/ ugd/3cf4ac_5f9a1756f9d743cab9c232915934459c.pdf

Bolívar, M. (s.f.). Las medidas cautelares innominadas y su relación con el principio de legalidad. Universidad católica de Colombia. Bogotá D.C. Recuperado de: https://repository.ucatolica.edu.co/bitstream/10983/16182/1/MEDIDAS\%20 CAUTELARES\%20INNOMINADAS\%20Y\%20SU\%20RELACION\%20CON\%20EL\%20 PRINCIPIO\%20DE\%20LEGALIDAD.pdf

Calamandrei, P. (1984). Providencias cautelares. Buenos Aires, Argentina: Editorial Bibliográfica Argentina. Recuperado de http://www.venezuelaprocesal.net/ Calmandreimedidas.pdf

Contreras, J. (2015). Medidas cautelares innominadas y anticipatorias un análisis comparado en las distintas jurisdicciones del régimen jurídico colombiano. 
Universidad católica de Colombia. Bogotá D.C. Recuperado de: https://repository. ucatolica.edu.co/bitstream/10983/2330/1/Medidas\%20cautelares\%20 innominadas $\% 20 y \% 20$ anticipatorias $\% 20$ un $\% 20$ an\%C3\%A1lisis $\% 20$ comparado\%20en\%20las\%20distintas\%20jurisdicci.pdf

Concepto del 16 de marzo de 2016. Superintendencia de Industriay Comercio. Recuperado de: https://bibliotecadigital.ccb.org.co/bitstream/handle/11520/17206/ Superlndustria-Concepto-0026046_20160316\%20 compartir\%20 informaci\%C3\%B3n\%20del\%20producto\%20con\%20competencia\%20directa. pdf?sequence $=1 \&$ isAllowed $=y$

Cuellar, G y Villamizar K. (2015). El principio de proporcionalidad en las medidas cautelares innominadas como garantía a la tutela jurisdiccional efectiva en la jurisdicción ordinaria civil colombiana. Universidad Libre - Seccional Cúcuta. Cúcuta, Colombia. Recuperado de: http://repository.unilibre.edu.co/bitstream/ handle/10901/9564/EL\%20PRINCIPIO\%20DE\%2OPROPORCIONALIDAD\%20 EN\%20LAS\%20MEDIDAS\%20CAUTELARES\%2OINNOMINADAS\%20COMO\%20 GARANTIA\%20A\%20LA\%20TUTELA\%20.pdf?sequence=1.

Delgado Peña. P. (Julio-Diciembre 2015). Cláusula de prohibición general de competencia desleal. Revista CES Derecho. 6 (2), 93-107. Recuperado de http://www.scielo. org.co/pdf/cesd/v6n2/v6n2a07.pdf

Ley 256 de 1996 por el cual se regula la competencia desleal. Recuperado de: http:// www.secretariasenado.gov.co/senado/basedoc/ley_0256_1996.html

Ley 1564 de 2012 por medio del cual se expide el Código General del Proceso. Recuperado de: http://www.secretariasenado.gov.co/senado/basedoc/ley_1564_2012.html

Ley 178 de 1994 por el medio de la cual se aprueba el Convenio de París para la Protección de la Propiedad Industrial. Recuperado de: http://www.secretariasenado.gov.co/ senado/basedoc/ley_0178_1994.html

Parra J. (2013). Medidas cautelares innominadas. Bogotá, Colombia: Editorial Universidad Libre. Recuperado de https://letrujil.files.wordpress.com/2013/09/12jairo-parra-quijano.pdf

Resolución No. 7335 del 22 de marzo de 2016. Superintendencia de Industria y Comercio. Recuperado de http://www.sic.gov.co/sites/default/files/estados/ RESOLUCION_7335_DE_22_DE_FEBRERO_DE_2016\%20-NIEGA_MEDIDAS_ CAUTELARES_COMITE_PRO_DEFENSA.pdf 
Superintendencia de industria y comercio. (2006). Compendio de doctrina yjurisprudencia de competencia desleal. Recuperado de http://www.sic.gov.co/recursos_user/ documentos/compendio/Competencia_Desleal.pdf

Sandoval, J. (2016). Medidas cautelares innominadas en procesos de competencia desleal y en acciones por infracción de derechos de propiedad intelectual ¿un camino hacia el prejuzgamiento? Revista del Instituto Colombiano de Derecho Procesal. (43), 153-176. Recuperado de: http://publicacionesicdp.com/index. php/Revistas-icdp/article/view/408/pdf

Trujillo L., F. (2014). Las medidas cautelares en el contexto del Código General del Proceso colombiano. Criterio Jurídico Garantista. 6 (11), 176-185. Bogotá D.C. Recuperado de: file:///C:/Users/internet/Downloads/446-Texto\%20del\%20art\%C3\%ADculo838-1-10-20150830.pdf

Uribe, A. (2014). Análisis del régimen general de las acciones por competencia desleal. Universidad Pontificia Bolivariana. Medellín, Colombia. Recuperado de: https:// repository.upb.edu.co/bitstream/handle/20.500.11912/2287/Monografia\%20 Andres\%20Uribe\%20aprobada\%2025.09.14.pdf?sequence=1 